\section{MYC rearrangement but not extra MYC copies is an independent prognostic factor in patients with mantle cell lymphoma}

\author{
Lifu Wang, ${ }^{1,2}$ Guilin Tang, ${ }^{1} \mathrm{~L}$. Jeffrey Medeiros, ${ }^{1}$ Jie $\mathrm{Xu},{ }^{1}$ Wenting Huang,,${ }^{1,3}$ \\ C. Cameron Yin, ${ }^{1}$ Michael Wang, ${ }^{4}$ Preetesh Jain, ${ }^{4}$ Pei Lin ${ }^{1}$ and Shaoying $\mathrm{Li}^{1}$
}

${ }^{1}$ Department of Hematopathology, The University of Texas MD Anderson Cancer Center, Houston, TX, USA; '2Department of Pathology, Henan Provincial People's Hospital, Zhengzhou, Henan, China; ${ }^{3}$ Department of Pathology, National Cancer Center/Cancer Hospital, Chinese Academy of Medical Sciences and Peking Union Medical College, Beijing, China and ${ }^{4}$ Department of Lymphoma and Myeloma, The University of Texas MD Anderson Cancer Center, Houston, TX, USA

\section{ABSTRACT}

M antle cell lymphoma (MCL) with $M Y C$ rearrangement (MYC-R) is rare and little is known about the importance of $M Y C$ extra copies (EC) in the absence of MYC-R in MCL patients. This study includes $88 \mathrm{MCL}$ patients with MYC tested by fluorescence in situ hybridization and/or conventional cytogenetics, including 27 with $M Y C-\mathrm{R}$, 21 with MYC-EC, and 40 with normal MYC-NL. MCL patients with MYC-R more often had blastoid/pleomorphic morphology; a higher frequency of CD10, MYC, and simultaneous MYC and BCL2 expression; a higher level of MYC; and a higher Ki67 proliferation rate $(P<0.05)$ than those without $M Y C-\mathrm{R}$. Although patients with $M Y C-\mathrm{R}$ more frequently received intensive chemotherapy $(P=0.001)$, their overall survival $(O S)$ was significantly shorter than those without $M Y C-\mathrm{R}$. Compared with patients with MYC/BCL2 double-hit lymphoma (DHL), patients with MYC-R MCL had a similar OS but more commonly had bone marrow involvement, Ann Arbor stage IV disease, and a different immunophenotype. MCL patients with MYC-EC showed an OS intermediate between those with MYC-R and MYC-NL, either all or only blastoid/pleomorphic MCL patients included. Multivariate analysis showed that MYC-R, but not MYC-EC, had an independent and negative impact on OS. In conclusion, MYC-R but not MYC-EC showed a higher MYC expression and is an adverse prognostic factor for MCL patients. Although the OS of MCL patients with MYC-R is similar to that of $M Y C / B C L 2$ DHL patients, these groups have different clinicopathologic features supporting the retention of MCL with MYC-R in the category of $\mathrm{MCL}$, as recommended in the revised World Health Organization classification.

\section{Introduction}

Mantle cell lymphoma (MCL) is an aggressive, incurable B-cell lymphoma characterized by $\mathrm{t}(11 ; 14)(\mathrm{q} 13 ; \mathrm{q} 32)$ that juxtaposes the CCND1 gene adjacent to IGH on the derivative chromosome 14 . This translocation results in constitutive overexpression of cyclin D1 and deregulation of the cell cycle at the G1/S phase transition. ${ }^{1-3}$ Data from mouse models and clinical studies suggest that CCND1 is a weak oncogene and that secondary genetic aberrations likely contribute to MCL development. ${ }^{4,5}$ Furthermore, conventional cytogenetic studies have shown that the $\mathrm{t}(11 ; 14)$ is rarely an isolated genetic abnormality in MCL. The lymphoma cells display a high degree of genomic instability and tend to accumulate additional chromosomal and molecular alterations, which likely lead to clinical progression of disease. ${ }^{1,6,7}$

MYC is one of the most frequently deregulated oncogenes in human malignancies. $^{8,9} \mathrm{t}(8 ; 14)(\mathrm{q} 24 ; \mathrm{q} 32) / M Y C-I G H$ was the first recurrent translocation identified in lymphomas, initially in Burkitt lymphoma (BL). Subsequently, it was learned that
Ferrata Storti Foundation

Haematologica 2021

Volume 106(5):1381-1389

\section{Correspondence:}

SHAOYING LI

sli6@mdanderson.org

Received: November 13, 2019.

Accepted: March 27, 2020.

Pre-published: April 9, 2020.

https://doi.org/10.3324/haematol.2019.243071

(C)2021 Ferrata Storti Foundation

Material published in Haematologica is covered by copyright. All rights are reserved to the Ferrata Storti Foundation. Use of published material is allowed under the following terms and conditions:

https://creativecommons.org/licenses/by-nc/4.0/legalcode. Copies of published material are allowed for personal or internal use. Sharing published material for non-commercial purposes is subject to the following conditions:

https://creativecommons.org/licenses/by-nc/4.0/legalcode, sect. 3. Reproducing and sharing published material for commercial purposes is not allowed without permission in writing from the publisher. 
MYC can partner with immunoglobulin (Ig) and non-Ig genes in multiple types of $\mathrm{B}$-cell lymphoma including diffuse large B-cell lymphoma (DLBCL), high grade B-cell lymphoma (previously known as B-cell lymphoma, unclassifiable, with features intermediate between DLBCL and BL ${ }^{10-12}$ and rarely other small B-cell lymphomas, such as follicular lymphoma, chronic lymphocytic leukemia/small lymphocytic lymphoma and MCL. MYC alterations are often associated with an aggressive clinical course. . $^{3-19}$

Double-hit lymphoma (DHL) was defined broadly by Aukema et al..$^{20}$ as a mature B-cell lymphoma with a chromosomal breakpoint affecting the MYC locus combined with additional translocations involving other genes, such as $B C L 2, B C L 3, B C L 6$, or CCND1. The most common genetic combination in DHL is $M Y C / 8 q 24$ rearrangement and $\mathrm{t}(14 ; 18)(\mathrm{q} 32 ; \mathrm{q} 21) / I G H-B C L 2$, which represents about $65 \%$ of cases. ${ }^{20-22}$ Significant advances in the understanding of DHL have been made in recent years, and large B-cell lymphomas with $M Y C$ and $B C L 2$ and/or $B C L 6$ rearrangements were included in the category of high-grade B-cell lymphoma with $M Y C$ and $B C L 2$ and/or $B C L 6$ rearrangements in the 2017 World Health Organization (WHO) classification, except for cases that fulfill criteria for a follicular lymphoma, MCL, or lymphoblastic lymphoma. ${ }^{23}$ As a result, MCL with MYC rearrangement (MYC-R), although fulfilling the earlier concept of DHL suggested by Aukema and colleagues, remains in the category of MCL.

MCL associated with MYC-R is rare and only case reports and small case series have been reported previously. ${ }^{6,24-29}$ No study has explored the prognostic significance of MYC-R in MCL patients by comparing the survival of MCL patients with or without MYC-R. In addition, as we have studied cases of MCL by fluorescence in situ hybridization (FISH) to assess MYC we have come across cases of MCL with extra copies of MYC (MYC-EC), but without MYC-R. The prognostic impact of MYC-EC has not been well characterized previously.

In this study we had two aims. First, we addressed the prognostic impact of MYC-R in MCL patients, and in particular, is the prognosis more akin to that of patients with DHL with $M Y C$ and BCL2 rearrangements (MYC/BCL2 $\mathrm{DHL}$ ). Secondly, we addressed the question of the potential prognostic impact of $M Y C$-EC in the absence of $M Y C$ rearrangement in MCL patients.

\section{Methods}

\section{Case selection}

We searched the cytogenetic/FISH testing database of the Department of Hematopathology at The MD Anderson Cancer Center from January 1, 2004 to December 31, 2018 and identified 88 cases of MCL with 11913/CCND1 and 8924/MYC tested by FISH and/or conventional karyotyping. Only three cases were before 2010 and most cases were diagnosed in recent years. MYC-R in MCL is rare and there are no standard rules or criteria for which MCL should be tested for MYC FISH, so the choice of MYC FISH testing for MCL was solely at the discretion of the treating oncologist and diagnosing hematopathologist. However, in general it was performed on a small subset of blastoid/pleomorphic MCL and occasional classic MCL cases. Ninety-five cases of high-grade B-cell lymphoma with concurrent MYC and BCL2 rearrangements confirmed by FISH (MYC/BCL2 DHL) from the same time period were used as a comparison group. Clinical infor- mation was obtained by review of corresponding medical records, including lymphoma history, sites of involvement, stage, treatment and overall survival (OS). Morphologic, immunophenotypic and cytogenetic data were also reviewed. The diagnosis of all cases was made according to the criteria of the current WHO classification. ${ }^{10,11}$ The study was approved by the Institutional Review Board.

\section{Immunophenotypic methods}

Immunohistochemical stains were performed using formalinfixed, paraffin-embedded (FFPE) tissue sections, either at the time of diagnosis or retrospectively for the purpose of this study. The monoclonal antibodies used were specific for: CD3, CD5, CD10, CD20, BCL-2, BCL-6, IRF4/MUM-1, MYC, P53, Ki67, cyclin D1, and SOX-11. The positive cutoff was $\geq 30 \%$ for CD10, MUM-1, and $\mathrm{BCL}^{30} ; \geq 20 \%$ for $\mathrm{P}^{3} 3^{31} ; \geq 40 \%$ for $\mathrm{MYC}^{16} ; \geq 50 \%$ for BCL2 $2^{32}$ and $>10 \%$ for SOX $11^{33}$.

Flow cytometry immunophenotypic analysis was performed using either a FACScanto II or FACSCalibur cytometer (BectonDickinson Biosciences, San Jose, CA, USA) as described previously. ${ }^{34,35}$ Lymphocytes were gated for analysis using side scatter versus forward scatter, and CD45 versus side scatter. The panel of antibodies employed included CD3, CD5, CD10, CD11c, CD19, CD20, CD22, CD23, CD30, CD38, CD43, CD45, CD79b, CD200, FMC-7, and surface Ig $\kappa$ and $\lambda$ light chains. All antibodies were obtained from Becton-Dickinson Biosciences.

\section{Conventional cytogenetics and fluorescence in situ hybridization}

Conventional chromosomal analysis was performed on Gbanded metaphase cells prepared from cell suspensions from tissue biopsy specimens or bone marrow aspirates using standard techniques. The karyotype was reported according to the International System for Human Cytogenetic Nomenclature (2016). ${ }^{36}$ FISH was performed on bone marrow smears or $4-\mu \mathrm{m}$ thick FFPE tissue sections according to the manufacturer's instructions. A total of 200 interphase nuclei for each probe were analyzed. FISH probes used in this study included the following: locus specific identifier (LSI) IGH/CCND1 dual-color, dual fusion translocation probe; LSI MYC as well as BCL6 dual-color, breakapart probe; LSI IGH/BCL2 dual-color, dual-fusion translocation probe (Vysis/Abbott Laboratories, Des Plaines, IL, USA).

\section{Statistical analysis}

Overall survival (OS) was calculated from the date of initial diagnosis (for de novo cases) or the date that a MYC aberration was detected (for patients with $M Y C$ aberration detected at disease transformation or progression) to the date of death or last followup. Survival was analyzed using the Kaplan-Meier method and was compared by log-rank test (GraphPad Prism version 7 software). Fisher's exact test was utilized to compare the difference between groups. Multivariate Cox proportional hazard analysis was performed using SPSS 24.0 software. Differences between groups were considered statistically significant when the $P$-value is less than 0.05 .

\section{Results}

\section{Mantle cell lymphoma patients with MYC rearrangement Clinical characteristics}

Twenty-seven MCL patients had MYC-R, including 20 men and 7 women, with a median age of 63 years (range, 47 to 85 ). Fourteen (52\%) patients with $M Y C-\mathrm{R}$ presented 
Table 1. Comparison of features of mantle cell lymphoma with MYC rearrangment (MYC- $R$ ), mantle cell lymphoma without $M Y C-R$ and $M Y C / B C L 2$ double-hit lymphoma.

\begin{tabular}{|c|c|c|c|c|c|}
\hline \multirow[t]{2}{*}{ Features } & \multirow{2}{*}{$\begin{array}{l}\text { MCL with } \\
\text { MYC-R } \\
(n=27)\end{array}$} & \multirow{2}{*}{$\begin{array}{l}\text { MCL with } \\
\text { non-MYY-R } \\
(n=61)\end{array}$} & \multirow{2}{*}{$\begin{array}{l}\text { MYC/BCL2 } \\
\text { DHL }(\mathrm{n}=95)\end{array}$} & \multicolumn{2}{|c|}{$P$ value of MCL with MYC-R } \\
\hline & & & & $\begin{array}{l}\text { vs. MCL without } \\
\text { MYC-R }\end{array}$ & $\begin{array}{c}\text { vs. MYC/BCL2 } \\
\text { DHL }\end{array}$ \\
\hline Age (years), Median (range) & $63(47-85)$ & $61.5(33-85)$ & $60.5(33-86)$ & 0.25 & 0.21 \\
\hline Age $\geq 60$ (years) & $67 \%(18 / 27)$ & $54 \%(33 / 61)$ & $59 \%(56 / 95)$ & 0.21 & 0.32 \\
\hline Sex (Male:Female) & $20: 7$ & 44:17 & 64:31 & 0.80 & 1.00 \\
\hline Stage IV & $92 \%(24 / 26)$ & $92 \%(55 / 60)$ & $66 \%(58 / 88)$ & 1.00 & $0.01 *$ \\
\hline BM-Positve & $96 \%(23 / 24)$ & $83 \%(50 / 60)$ & $44 \%(33 / 75)$ & 0.17 & $0.0001^{*}$ \\
\hline CNS-Positve & $33 \%(4 / 12)$ & $21 \%(4 / 19)$ & $13 \%(7 / 52)$ & 0.68 & 0.20 \\
\hline Extranodal Sites $\geq 2$ & $77 \%(20 / 26)$ & $68 \%(39 / 57)$ & $56 \%(49 / 88)$ & 0.61 & 0.11 \\
\hline Elevated LDH (>618 U/L) & $65 \%(17 / 26)$ & $46 \%(23 / 50)$ & $86 \%(55 / 64)$ & 0.22 & $\mathbf{0 . 0 3}^{*}$ \\
\hline Elevated WBC $\left(>11.0 \times 10^{6} / \mu \mathrm{L}\right)$ & $40 \%(10 / 25)$ & $44 \%(22 / 50)$ & & 0.81 & \\
\hline High MIPI/High or High-Intermediate IPI & $58 \%(15 / 26)$ & $44 \%(22 / 50)$ & $85 \%(60 / 71)$ & 0.32 & \\
\hline \multicolumn{6}{|l|}{ Morphology for MCL } \\
\hline Classic & $11 \%(3 / 27)$ & $46 \%(28 / 61)$ & & & \\
\hline Blastic/Pleomorphic & $89 \%(24 / 27)$ & $54 \%(33 / 61)$ & & $0.004^{*}$ & \\
\hline Leukemic Non-Nodal & $26 \%(7 / 27)$ & $26 \%(16 / 61)$ & & 0.88 & \\
\hline \multicolumn{6}{|l|}{ Immunophenotype } \\
\hline $\mathrm{SOX}_{11^{+}}$ & $70 \%(7 / 10)$ & $90 \%(28 / 31)$ & & 0.14 & \\
\hline $\mathrm{BCL}^{+}$ & $31 \%(4 / 13)$ & $26 \%(8 / 31)$ & $93 \%(68 / 73)$ & 0.73 & $0.0001^{*}$ \\
\hline $\mathrm{CD}^{+}$ & $73 \%(19 / 26)$ & $87 \%(53 / 61)$ & $5 \%(3 / 63)$ & 0.11 & $0.0001^{*}$ \\
\hline $\mathrm{CD} 10^{+}$ & $35 \%(9 / 26)$ & $11 \%(6 / 56)$ & $96 \%(87 / 91)$ & $0.01 *$ & $0.0001^{*}$ \\
\hline MUM-1 ${ }^{+}$ & $50 \%(4 / 8)$ & $67 \%(6 / 9)$ & $31 \%(14 / 45)$ & 0.64 & 0.42 \\
\hline BCL2 ( $\geq 50 \%)$ & $86 \%(12 / 14)$ & $97 \%(28 / 29)$ & $94 \%(83 / 88)$ & 0.22 & 0.22 \\
\hline MYC ( $(\geq 40 \%)$ & $80 \%(12 / 15)$ & $17 \%(6 / 36)$ & $85 \%(39 / 46)$ & $0.0001^{*}$ & 0.70 \\
\hline MYC/BCL2 dual-expression & $69 \%(9 / 13)$ & $9 \%(3 / 33)$ & $78 \%(36 / 46)$ & $0.0001^{*}$ & 0.46 \\
\hline P53 ( $\geq 20 \%)$ & $71 \%(12 / 17)$ & $65 \%(13 / 20)$ & $63 \%(12 / 19)$ & 1.00 & 0.73 \\
\hline Ki67, Median(range) & $90(15-100)$ & $60(2-100)$ & $85(20-100)$ & $0.004^{*}$ & 0.53 \\
\hline \multicolumn{6}{|l|}{ Treatment } \\
\hline Intensive chemotherapy & $67 \%(16 / 24)$ & $24 \%(13 / 54)$ & $51 \%(44 / 86)$ & $0.001 *$ & 0.25 \\
\hline Other immuno/chemotherapy & $33 \%(8 / 24)$ & $74 \%(40 / 54)$ & $49 \%(42 / 86)$ & & \\
\hline Initial CR & $33 \%(8 / 24)$ & $62 \%(29 / 47)$ & $32 \%(27 / 85)$ & $0.03^{*}$ & 1.00 \\
\hline
\end{tabular}

Blank: not available; BM: bone marrow; CNS: central nervous system; CR: complete remission;LDH: lactate dehydrogenase; MIPI: Mantle Cell Lymphoma International Prognostic Index; MCL: mantle cell lymphoma; DHL: double hit lymphoma; intensive chemotherapy (R-CHOP): rituximab, cyclophosphamide, doxorubicin, vincristine, prednisone; other immuno/chemotherapy (R-Hyper-CVAD): rituximab, cyclophosphamide, vincristine, doxorubicin, dexamethasone; WBC: white blood cell; ${ }^{*} P<0.05$.

with de novo MCL and $13(48 \%)$ patients acquired MYC-R at time of disease progression or transformation from classic to blastoid/pleomorphic MCL. There were 13 $(48 \%)$ cases diagnosed initially in lymph nodes, 11 (41\%) cases in bone marrow and three cases in other tissue sites. Most patients presented with high stage (Ann Arbor stage IV) disease, high frequency of involvement of bone marrow or other extranodal sites, and elevated white blood cell (WBC) count and serum lactate dehydrogenase (LDH) level (Table 1). The involved extranodal sites included the bone marrow, spleen, central nervous system, gastrointestinal tract, peripheral blood, pleural fluid, pancreas, chest wall and soft tissue. A leukemic non-nodal form of MCL, defined as MCL with peripheral blood, bone marrow and sometimes spleen involvement but without significant lymphadenopathy by WHO classification, was present in seven $(26 \%)$ patients. Twenty-six patients had available clinical data to calculate the Mantle Cell Lymphoma International Prognostic Index (MIPI) score ${ }^{37}$ and $15(58 \%)$ patients had a high-risk MIPI score (Table 1$)$.

\section{Pathologic characteristics}

Twenty-four (89\%) cases of MCL associated with MYC-R cases had blastoid $(\mathrm{n}=19)$ (Figure 1) or pleomorphic $(n=5)$ morphologic features and three cases were classic type. Eleven of $14(79 \%)$ de novo MCL with MYC-R showed blastoid $(n=10)$ or pleomorphic $(n=1)$ morphology. All 13 patients with MCL that acquired MYC-R during disease progression presented with classic MCL at initial diagnosis, but had blastoid $(n=9)$ or pleomorphic $(n=4)$ morphology at the time of emergence of $M Y C-\mathrm{R}$.

All lymphomas were positive for one or more pan-B-cell antigens and were negative for pan- $\mathrm{T}$ cell antigens. As expected, all MCL with MYC-R cases expressed cyclin D1 (27 of $27,100 \%$ ), and most cases expressed SOX11 (7 of $10,70 \%)$, and MYC (12 of 15, 80\%). Concurrent MYC and BCL2 expression was observed in 9 of 13 (69\%) MCL cases assessed. Nineteen of $26(73 \%)$ cases were positive for CD5 (one case not assessed); the CD5-negative cases included four de novo MCL, two neoplasms which apparently lost CD5 at the time of detection of MYC-R, and one 


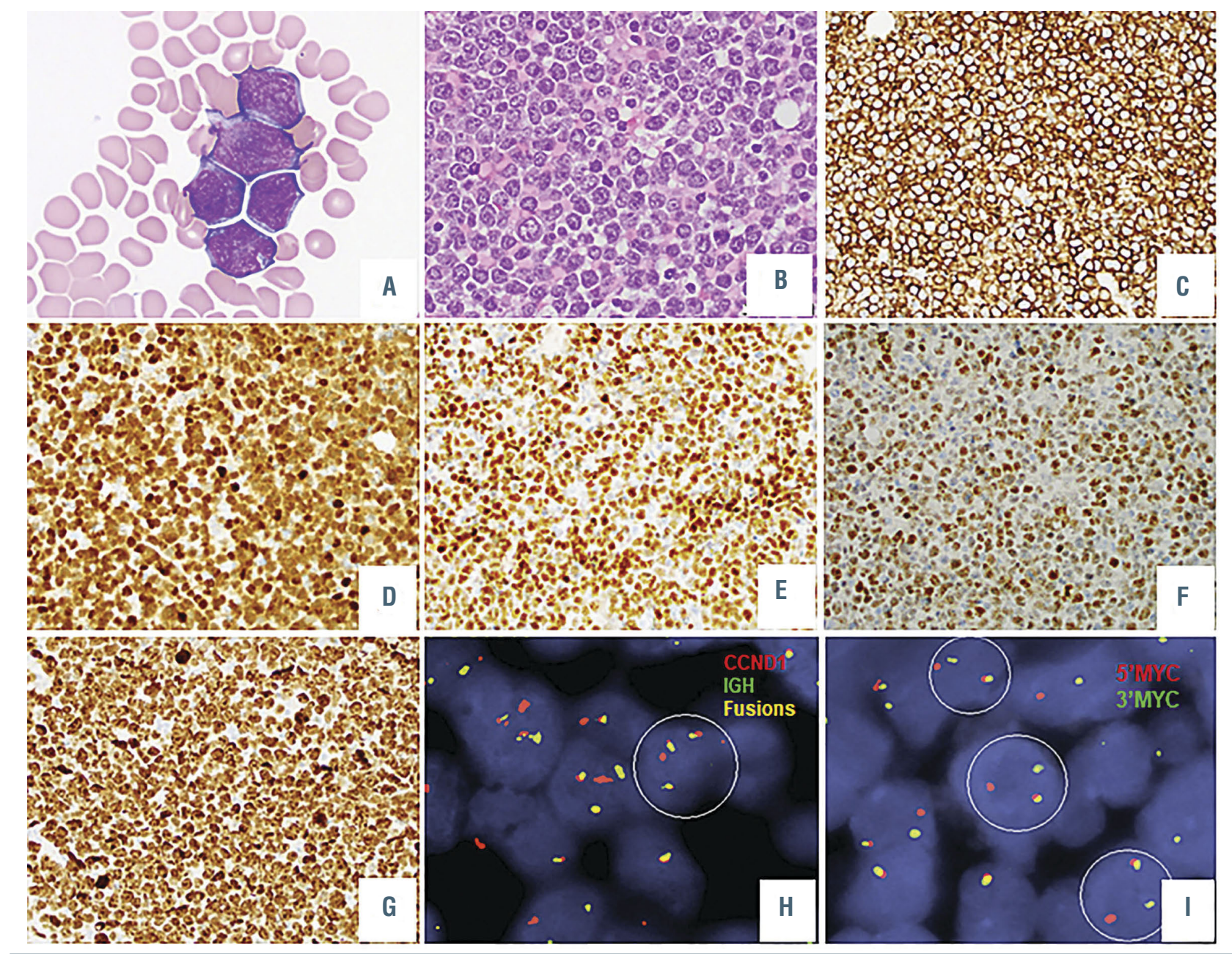

Figure 1. A representative case of mantle cell lymphoma with MYC rearrangement. The lymphoma cells have blastoid morphology. (A) Peripheral blood, (B) core biopsy, and express CD20 (C), cyclinD1 (D), MYC (E), BCL6 (F), and with a high Ki67 proliferation rate (G). Fluorescence in situ hybridization study showed CCND1/IGH (H) and MYC rearrangement (I).

case that was originally CD5-negative and developed MYC-R subsequently. CD10 was positive in 9 of 26 (35\%) cases assessed; CD10 was acquired at the time of transformation when $M Y C-\mathrm{R}$ emerged. All CD10+ cases had blastoid morphology. Four CD10+ MCL cases were CD5-negative. BCL-2 was positive in 12 of $14(86 \%)$ cases of MCL with $M Y C$-R. IRF4/MUM-1 and BCL- 6 were positive in 4 of $8(50 \%)$ and 4 of $13(31 \%)$ cases assessed, respectively. Twelve of 17 (71\%) cases showed P53 expression in more than $20 \%$ of cells, including all 9 cases $(100 \%)$ of transformed MCL and 4 of the $8(50 \%)$ de novo MCL cases tested. The Ki67 proliferation index was variable, but most cases had a high proliferation rate with a median Ki67 index of $90 \%$ (range, 15-100\%; only three cases had Ki67<60\%). All tested cases were negative for CD23 and CD200 (Table 1).

FISH showed MYC-R and CCND1 translocation in all 27 cases. One case showed both MYC-R and MYC-EC. Since there is only one such case, it was included in the MYC-R group. Conventional cytogenetic analysis was available in 18 cases and all showed a complex karyotype, including $\mathrm{t}(11 ; 14)(\mathrm{q} 13 ; \mathrm{q} 32)$ in 17 cases. By combined FISH and karyotype, 18q21/BCL2 and 3q27/BCL6 status were available in 19 cases and all were negative for rearrangement except one case with BCL6-R. Based on identifiable karyotype data, seven cases had MYC partner gene as $I G$ gene and three with non- $I G$ gene.

\section{Treatment and prognosis}

Detailed therapy data were available for 24 of $27 \mathrm{MCL}$ patients with MYC-R. All patients were treated with combination chemotherapy: sixteen (67\%) patients received intensive induction chemotherapy, mainly rituximab, hyperfractionated cyclophosphamide, vincristine, doxorubicin, and dexamethasone alternating with methotrexate and cytarabine) (R-Hyper-CVAD, $\mathrm{n}=14$ ) or rituximab, etoposide, prednisone, vincristine, and doxorubicin (R-EPOCH, n=2). Eight (33\%) patients received $\mathrm{R}-\mathrm{CHOP}$ (cyclophosphamide, doxorubicin, vincristine, and prednisone) or R (rituximab) and bendamustine. Eight (33\%) patients reached complete remission (CR) after induction, but six relapsed. Seven patients received a stem cell transplant (SCT), including four autologous and three allogeneic. After a median followup of 41.5 months, 17 of $24(71 \%)$ patients died including 10 patients with $M Y C-\mathrm{R}$ detected during disease progression/transformation. The median OS was 19.9 months and the 3 -year OS rate was $33 \%$ for all 27 patients. The median OS was worse for patients with MCL in whom MYC-R emerged during disease progres- 
Table 2. Comparision of features of blastoid mantle cell lymphoma wih MYC rearrangement and without MYC rearrangement.

\begin{tabular}{|c|c|c|c|}
\hline Features & $\begin{array}{l}\text { Blastoid MCL with } \\
\text { MYC-R (n=24) }\end{array}$ & $\begin{array}{l}\text { Blastoid MCL with } \\
\text { Non- MYC-R (n=29) }\end{array}$ & $P$ \\
\hline Age(years), Median (range) & $63(47-82)$ & $67(33-85)$ & 0.96 \\
\hline Age $\geq 60$ (years) & $71 \%(17 / 24)$ & $62 \%(18 / 29)$ & 0.76 \\
\hline Sex (Male:Female) & $17: 7$ & $20: 7$ & 0.75 \\
\hline Stage IV & $91 \%(20 / 22)$ & $89 \%(24 / 27)$ & 1.00 \\
\hline BM-Positve & $86 \%(18 / 21)$ & $74 \%(20 / 27)$ & 0.72 \\
\hline CNS-Positve & $40 \%(4 / 10)$ & $29 \%(4 / 14)$ & 0.67 \\
\hline Extranodal Sites $\geq 2$ & $80 \%(16 / 20)$ & $88 \%(22 / 25)$ & 0.61 \\
\hline Elevated LDH (>618 U/L) & $68 \%(15 / 22)$ & $62 \%(13 / 21)$ & 0.99 \\
\hline Elevated WBC $\left(>11.0 \times 10^{6} / \mu \mathrm{L}\right)$ & $40 \%(8 / 20)$ & $30 \%(6 / 20)$ & 0.74 \\
\hline High MIPI & $57 \%(12 / 21)$ & $53 \%(9 / 17)$ & 1.00 \\
\hline Leukemic Non-Nodal & $24 \%(5 / 21)$ & $7.4 \%(2 / 27)$ & 0.22 \\
\hline Complex Karyotype & $100 \%(16 / 16)$ & $100 \%(12 / 12)$ & 1.00 \\
\hline \multicolumn{4}{|l|}{ Immunophenotype } \\
\hline $\mathrm{SOX}_{1} 1^{+}$ & $73 \%(8 / 11)$ & $88 \%(15 / 17)$ & 0.28 \\
\hline $\mathrm{BCL}^{+}$ & $33 \%(4 / 12)$ & $33 \%(7 / 21)$ & 1.00 \\
\hline $\mathrm{CD}^{+}$ & $78 \%(18 / 23)$ & $81 \%(22 / 27)$ & 0.72 \\
\hline $\mathrm{CD} 10^{+}$ & $39 \%(9 / 23)$ & $12 \%(3 / 25)$ & $0.046^{*}$ \\
\hline $\mathrm{MUM}^{+} \mathrm{1}^{+}$ & $50 \%(4 / 8)$ & $71 \%(5 / 7)$ & 0.59 \\
\hline $\mathrm{BCL}^{+}(\geq 50 \%)$ & $86 \%(12 / 14)$ & $95 \%(19 / 20)$ & 0.54 \\
\hline $\mathrm{MYC}^{+}(\geq 40 \%)$ & $80 \%(12 / 15)$ & $20 \%(4 / 20)$ & $0.001 *$ \\
\hline MYC/BCL2 co-express & $69 \%(9 / 13)$ & $16 \%(3 / 19)$ & $0.004^{*}$ \\
\hline $\mathrm{P}^{3} 3^{+}(\geq 20 \%)$ & $75 \%(12 / 16)$ & $69 \%(9 / 13)$ & 0.97 \\
\hline Ki67, Median (range) & $90(15-100)$ & $90(30-100)$ & 0.37 \\
\hline \multicolumn{4}{|l|}{ Treatment } \\
\hline Aggressive chemotherapy & $68 \%(15 / 22)$ & $38 \%(10 / 26)$ & 0.08 \\
\hline Other chemotherapy & $32 \%(7 / 22)$ & $62 \%(16 / 26)$ & 0.15 \\
\hline Initial CR & $55 \%(12 / 22)$ & $70 \%(16 / 23)$ & 0.34 \\
\hline
\end{tabular}

BM: bone marrow; CNS: central nervous system; CR: complete remission; LDH: lactate dehydrogenase; MYC-R: MYC rearrangement; N: number of cases; MIPI: Mantle Cell Lymphoma International Prognostic Index; aggressive chemotherapy (R-CHOP): rituximab, cyclophosphamide, doxorubicin, vincristine, prednisone; other chemotherapy (R-Hyper-CVAD): rituximab, cyclophosphamide, vincristine, doxorubicin, dexamethasone; SCT: stem cell transplant; WBC: white blood cell; ${ }^{*} P<0.05$

sion/transformation than for patients with de novo MCL with MYC-R (Figure 2A, $P=0.019$ ).

\section{Mantle cell lymphoma with MYC rearrangement versus non-MYC rearrangement}

In addition to the $27 \mathrm{MCL}$ patients with MYC-R, 21 patients had $M Y C-\mathrm{EC}$, and 40 patients had MYC-NL. The 21 MCL cases with MYC-EC showed a median MYC copy number of 3.5 (range, 3-6); most cases had 3-4 copies. OS was compared among these subgroups and showed that patients with MCL associated with MYC-R had the poorest OS. Patients with MYC-NL MCL subgroup had the best OS and patients with MYC-EC group had an intermediate prognosis, closer to patients in the MYC-NL subgroup $(P=0.34)$ than the $M Y C-\mathrm{R}$ subgroup $(P=0.074)$ (Figure $2 \mathrm{~B}$, overall $P=0.0007)$. Therefore, we combined the MYC-EC and MYC-NL patients into a non- $M Y C-\mathrm{R}$ group to compare with the MYC-R group. Cases of MCL with MYC-R more frequently showed blastoid/pleomorphic morphology ( $89 \%$ vs. $54 \%, P=0.004)$, more often expressed CD10 ( $P=0.01)$, MYC $(P=0.0001)$, and, more commonly showed coexpress of MYC and BCL-2 $(P=0.0001)$ and also had a higher Ki67 proliferation rate (median $90 \%$ vs. $60 \%)(P<0.004)$. All other clinicopathologic features, including the frequency of leukemic non-nodal form MCL, were similar between the two groups (Table 1). Patients with MYC-R less frequently reached $C R$ after induction chemotherapy than patients in the non- $M Y C-\mathrm{R}$ group ( $33 \%$ vs. $62 \%, P=0.03$ ), despite more often receiving intensive induction therapy. The median OS of MCL patients with MYC-R was significantly lower than that of patients in the non- $M Y C-\mathrm{R}$ group with 3 -year OS rates of $33 \%$ and $67 \%$, respectively (Figure 2C, $P=0.0002$ ). This result was also true when only de novo cases were included in the analysis (Figure 2D, $P=0.030)$.

Since $M Y C-\mathrm{R}$ occurred predominantly in blastoid/pleomorphic variants, a comparison of $\mathrm{MCL}$ with MYC-R versus non- $M Y C-\mathrm{R}$ was further explored in cases with only blastoid or pleomorphic morphology. There were 53 cases of MCL with blastoid/pleomorphic morphology, including 24 cases with MYC-R and 29 cases without MYC-R. As shown in Table 2, almost all clinicopathologic features, including P53 expression, frequency of a complex karyotype, and CR rate of patients with $M Y C-\mathrm{R}$ were very similar to patients with non-MYC-R, except that the MYC-R group of neoplasms were more often positive for MYC and CD10 $(P<0.05)$. The median OS of patients with $M Y C$-R was significantly worse than that of patients in the non-MYC-R subgroup when all blastoid/pleumor- 

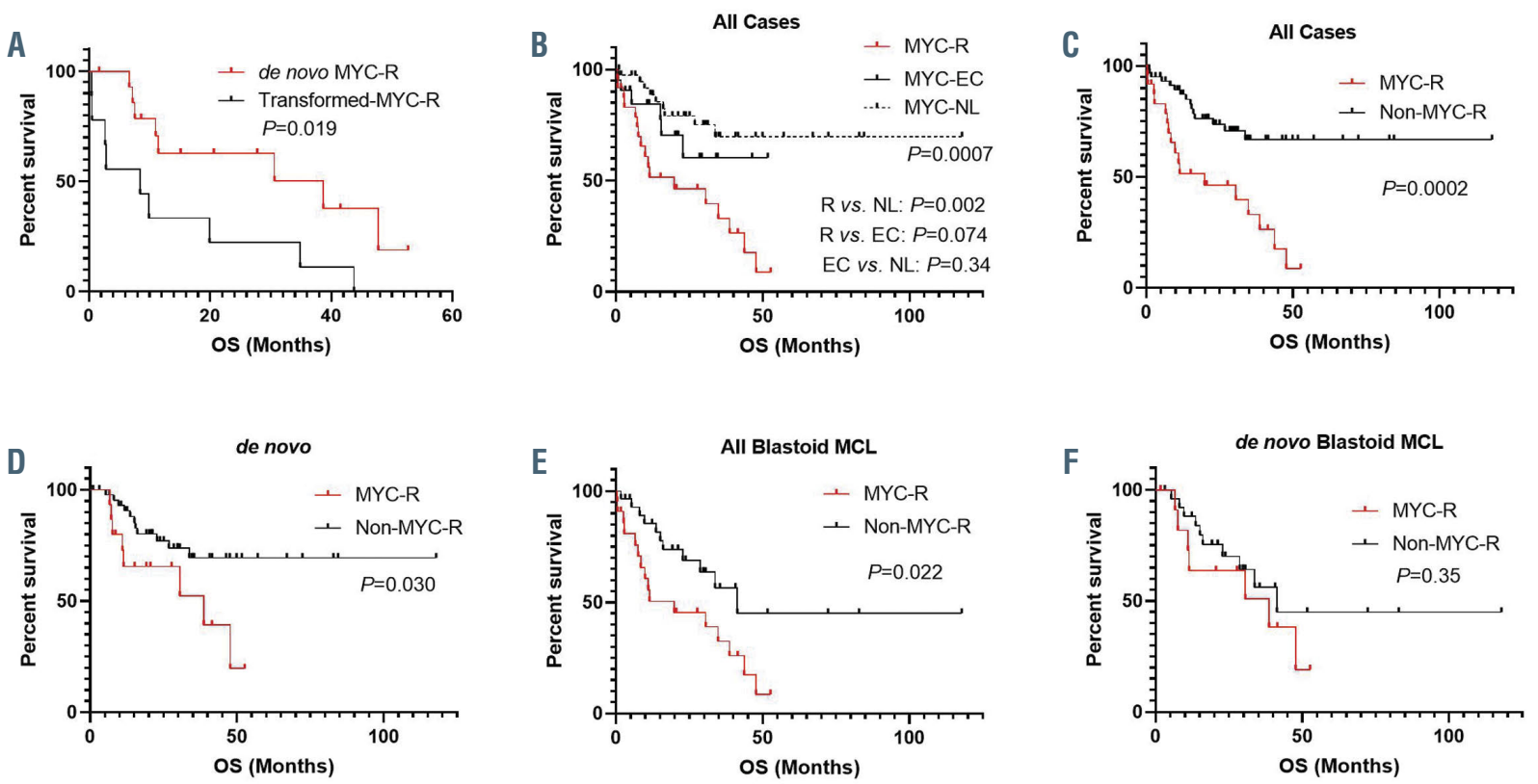

Figure 2. Comparison of median overall survival. There is a statistically significant difference in overall survival (OS) between de novo and transformed mantle cell lymphoma (MCL) with MYC rearrangement (MYC-R) (A); MCL with MYC-R and Non-MYC-R either all patients (C), only de novo cases (D), all blastoid MCL (E) or only de novo blastoid MCL $(F)$ were included. In all MCL patients, MYC-R group had the worst OS, MYC normal (MYC-NL) group the best OS, and MYC extra copies (MYC-EC) group laid in between (B).

phic patients were included (Figure 2E, $P=0.022$ ). However, there was no significant difference in median OS when only de novo blastoid/pleumorphic MCL patients were compared (Figure 2F, $P=0.35$ ).

\section{Correlation of MYC expression with MYC fluorescence in situ hybridization status in mantle cell lymphoma}

MYC immunohistochemical stains were performed on 51 cases of MCL, including 15 with $M Y C-\mathrm{R}, 15$ with $M Y C$ EC, and 21 with MYC-NL. MYC expression level showed a much wider distribution across samples in $M Y C-\mathrm{R}$ cytogenetic subgroup than $M Y C$-EC and $M Y C-\mathrm{R}$ subgroups due to the higher level of expression. The mean percentage of cells expressing MYC protein was significantly higher in the $M Y C-\mathrm{R}$ group than those in the MYC-EC and MYC-NL groups (50\%, range, $1-100 \%$ in the MYC-R group; $13 \%$, range, $0-55 \%$ in the MYC-EC group; and $15 \%$, range, $0-60 \%$ in the $M Y C-N L$ group; Figure $3 \mathrm{~A}$, $P<0.0001)$. There was no significant difference in the percentage of cells expressing MYC between the MYC-EC and $M Y C-\mathrm{NL}$ groups $(P=0.71)$. Although MCL cases with MYC-R demonstrated protein expression at variably high levels ( $\geq 40 \%$ in 12 of $15,80 \%$ of cases), slightly high MYC expression could occasionally occur in MCL without MYC-R. By using the $40 \%$ as a cut-off value for MYC immunohistochemistry to predict MYC-R, the sensitivity and specificity were $80 \%$ and $83 \%$ respectively.

\section{Multivariate analysis}

In order to further explore if MYC-R or MYC-EC were independent prognostic factors in MCL patients, multivariate Cox proportional hazard analysis was performed including MYC status and other factors that often predict survival in MCL, including morphology, Ki67 rate, and MIPI score. As shown in Table 3, MYC-R but not $M Y C$-EC was an independent prognostic factor for $O S$ in this cohort of MCL patients.
Table 3. Multivariate analysis.

\begin{tabular}{lccc} 
Features & TR & $95 \%$ Cl & $P$ \\
MYC-R & 3.27 & $1.149-9.306$ & $\mathbf{0 . 0 2 6}$ \\
MYC-EC & 2.375 & $0.632-8.923$ & 0.200 \\
\hline Blastoid/Pleumorphic MCL & 7.038 & $0.767-64.593$ & 0.073 \\
Ki67 $30 \%$ & 1.93 & $0.215-17.370$ & 0.557 \\
\hline High MIPI & 1.217 & $0.532-2.783$ & 0.642 \\
\hline
\end{tabular}

MYC-R: $M Y C$ rearrangement; $M Y C-E C: M Y C$ extra copies; MCL: mantle cell lymphoma; MIPI: Mantle Cell Lymphoma International Prognostic Index; HR: hazard ratio; CI: Confidence Interval; $P<0.05$

\section{Patients with mantle cell lymphoma associated with MYC rearrangement versus MYC/BCL2 double hit lymphoma patients}

The $27 \mathrm{MCL}$ patients with MYC-R were compared with 95 patients with $M Y C / B C L 2$ DHL (Table 1), the latter group including 67 patients with de novo DHL and 28 with DHL transformed from follicular lymphoma. While many clinicopathologic features were similar between these two groups, each group had some unique features. Patients with MCL harboring $M Y C-\mathrm{R}$ more often presented with bone marrow involvement (96\% vs. $44 \%, P=0.0001)$, Ann Arbor stage IV disease $(92 \%$ vs. $66 \%, P=0.01)$ and more frequent CD5 expression ( $71 \%$ vs. $5 \%, P=0.0001)$. In contrast, elevated serum LDH level and more frequent CD10 and BCL6 expression were observed more often in the $M Y C / B C L 2$ DHL group $(P<0.05$ for all).

There was no significant difference in $\mathrm{CR}$ rate between MCL patients with $M Y C-\mathrm{R}$ and patients with $M Y C / B C L 2$ DHL. Patients with MCL associated with $M Y C-\mathrm{R}$ had an inferior median OS compared with patients with $M Y C / B C L 2$ DHL (Figure 3B, $P=0.038$ ). However, there was no significant difference in $O S$ when patients with de novo MCL and MYC-R were compared to patients with de novo $M Y C / B C L 2$ DHL (Figure $3 C, P=0.83$ ). Since prognosis 
A

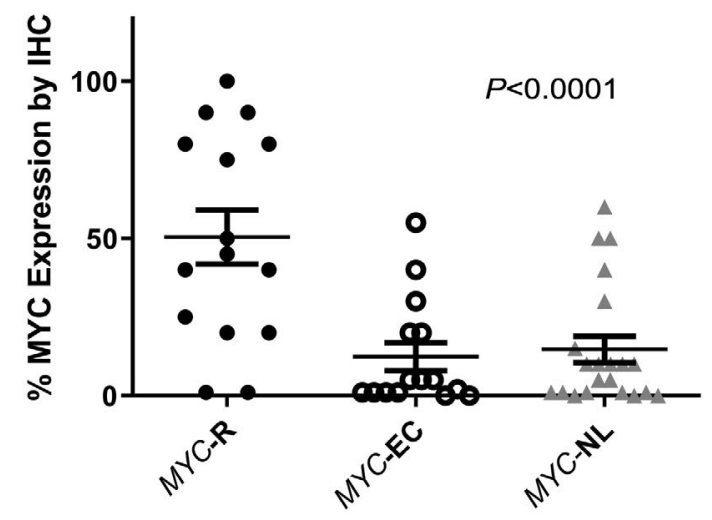

C

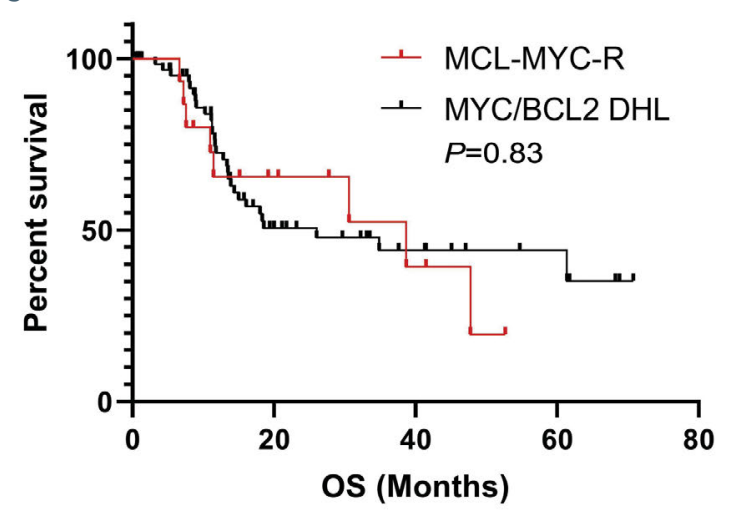

B
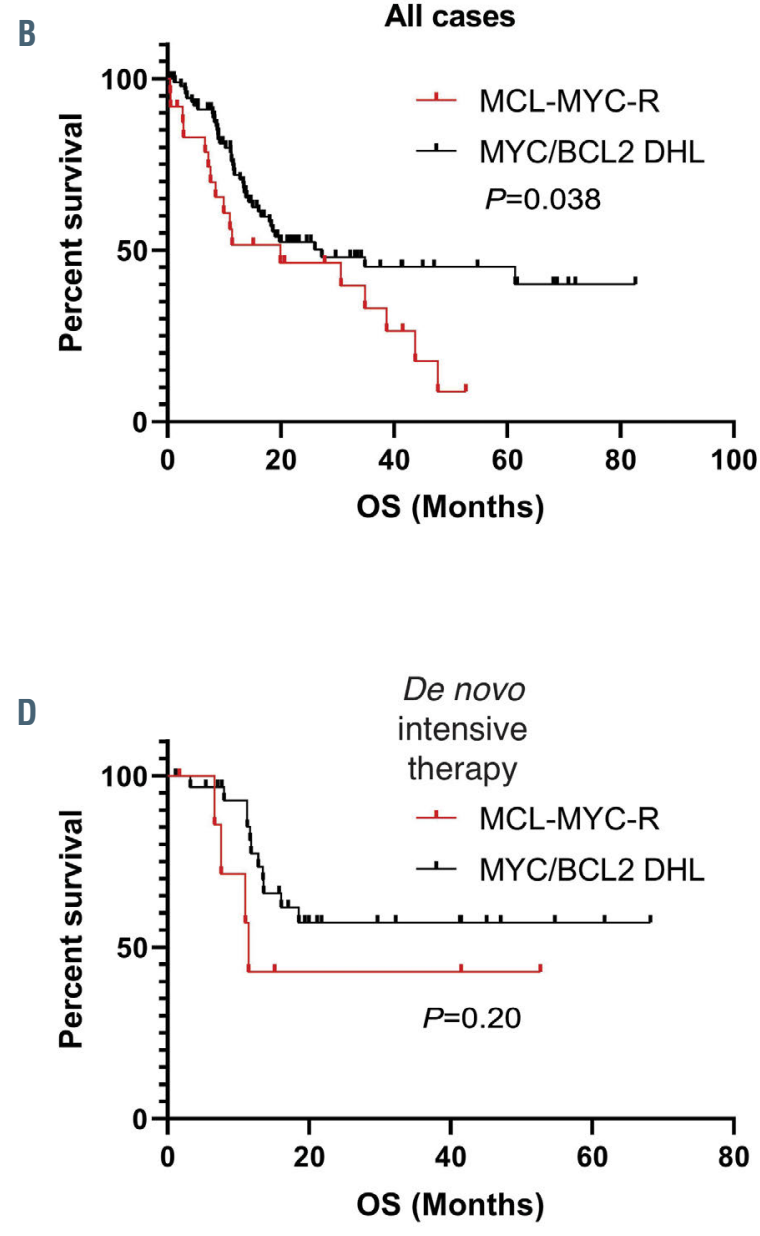

Figure 3. MYC protein expression in correlation with MYC cytogenetic status in mantle cell lymphoma. (A); Comparison of median overall survival (OS) between mantle cell lymphoma (MCL) with MYC rearrangement (MYC-R) and MYC/BCL2 double hit lymphoma (DHL): (B) All cases included; (C) Only de novo cases included; (D) Only patients who received intensive induction chemotherapy included.

is significantly related to the treatment regimens patients received and majority patients received intensive chemotherapy, we further compared the OS between patients who only received intensive induction immunochemotherapy (including R-Hyper-CVAD and $\mathrm{R}-\mathrm{EPOCH}$ ) in these two groups, and as shown in Figure $3 \mathrm{D}$, there was no significant difference in OS between the two sub-groups.

\section{Discussion}

MYC aberrations can occur rarely in cases of MCL. In this study, we collected $88 \mathrm{MCL}$ patients with known MYC status and explored the prognostic role of MYC aberrations. We show that MYC-R but not $M Y C$-EC is an independent adverse prognostic factor in MCL patients. We also compared the clinicopathologic features of MCL patients with $M Y C-\mathrm{R}$, so-called double hit MCL, to a large group of patients with $M Y C / B C L 2 \mathrm{DHL}$ and show some similarities and differences. To our knowledge, this is the largest series of MCL cases in which MYC status has been assessed.

MCL with $M Y C-\mathrm{R}$ has been reported previously, however, most studies have been case reports or small case series that were mainly descriptive and without a MYC-R control group to compare for clinicopathologic features and prognosis. ${ }^{6,24-29}$ In this study, by comparing to a control group of $61 \mathrm{MCL}$ cases without MYC-R, MCL cases with MYC-R demonstrated some unique clinicopathologic features: more frequently have blastoid/pleomorphic morphology, more frequently express CD10, MYC, MYC and BCL2 co-expression, with a higher Ki67 proliferation rate and an inferior OS. It is well known that blastoid and pleomorphic variants of $\mathrm{MCL}$ has a poorer prognosis. In order to exclude the effect of morphology, the role of MYC-R was further evaluated in blastoid/pleomorphic MCL cases, which showed MYC-R was associated with higher MYC expression and expression of CD10 and a poorer OS, especially in transformed MCL cases. However, there are many other potential factors involved when patients with MCL undergo progression or transformation. In order to further exclude other possible confounding factors, a multivariate analysis was performed and demonstrated that MYC-R is an independent poor prognostic factor in MCL patients.

MYC (8q24) is an essential global transcription factor that controls $10-15 \%$ of all human genes and regulates many cellular functions including cell cycle, cell growth, metabolism, biosynthesis, survival, and apoptosis. Dysregulation of MYC induces lymphomagenesis. In BL, $M Y C-\mathrm{R}$ is the primary event and mainly translocated with 
IGH. In MCL, CCND1 rearrangement is the primary event and MYC-R is likely a secondary event, which is further suggested by the more frequent translocation with IG light chain genes or non- $I G$ genes in our current study. Many oncogenes function by activation mutations or forming oncogenic fusion proteins, however, $M Y C$ works differently by loss of tight control of intact MYC at both the transcriptional and translational levels. MYC protein can be upregulated by three major mechanisms, among which MYC translocation and amplification are two of them. This is evidenced by the current findings of significantly higher level of MYC protein expression and worse OS in the MYC-R MCL group than the two groups without $M Y C-R$.

Fifteen patients originally diagnosed with classic variant MCL underwent disease progression/transformation to blastoid/pleomorphic variant of MCL during or after initial treatment. $M Y C-R$ was detected at the time of disease transformation in $13(87 \%)$ of these patients, MYC-EC (45 copies) was detected in one patient, and no MYC aberration was detected in one patient. These data suggest that MYC-R is involved in MCL disease progression and transformation and also contributed to a poorer prognosis. This finding also confirmed the observation of a few case reports in the literature that described the emergence of MYC-R at time of MCL progression or transformation. ${ }^{24,26,38}$ Previous studies shown $M Y C$ co-operated with transcriptionally activated cyclinD1 and resulted in blastoid MCL or oncogenic transformation of B-cell lymphoma in mouse models. ${ }^{5,39}$ Studies also demonstrated that MYC plays an important role in intrinsic ibrutinib resistance in MCL, possibly by repressing miR15a and miR16-1, two tumor suppressor microRNA involved in MCL pathogenesis. ${ }^{40,41}$ These mechanisms may explain the role of MYC-R in MCL progression or transformation. Of note, secondary MYC translocation is often associated with genomic instability and a complex karyotype. Except activating of $M Y C$, many other factors may also contribute to MCL disease progression and transformation, such as inactivation of CDKN2A and TP53 genes, gain or loss of other chromosomes and gene mutations. In our current study, all 18 cases of MYC-R MCL with karyotype available showed a complex karyotype, and all nine cases with P53 expression data available showed an over expression of P53 (seven cases with P53 $>80 \%$ and two cases 50\%). These results confirmed the above points. Although only a very small number of progressed or transformed MCL cases were tested for MYC-R by FISH, it is reasonable to conclude that MYC-R is associated with MCL progression or transformation at lease in a subset of MCL patients.

In this study, the MYC protein expression level is significantly higher in MCL with $M Y C-R$ than those without MYC-R (MYC $>40 \%$ in $80 \%$ vs. $17 \%$ of cases respectively). These findings are consistent with previously reported MYC expression in MCL and our previous study of MYC expression in DLBCL. ${ }^{42-44}$ Our results also demonstrate that using $40 \%$ as a cut-off, MYC immunohistochemistry can predict $M Y C$-R with a sensitivity of $80 \%$ and a specificity of $83 \%$, better than those reported for DLBCL which has a similar sensitivity but much lower specificity of $61 \%{ }^{44}$ Based on our results and the aggressiveness of
MCL with MYC-R, we recommend using MYC immunohistochemistry of $>40 \%$ as a screening tool to test MYC by FISH in all blastoid/pleomorphic MCL cases for cost effective practice.

A few cases of MCL with MYC-EC have been described in the literature. ${ }^{6,28,45}$ Yi et al. ${ }^{46}$ reported 14 patients with $M Y C$-EC and four patients with MYC-R and these 18 patients had a poorer prognosis than a comparison group of MCL patients without MYC abnormalities. ${ }^{46}$ To date, we are not aware of any prognostic studies for a pure group of MCL patients with MYC-EC without $M Y C$-R. In this study, the prognostic effect of MYC-EC lie in between MYC-NL and MYC-R groups in patients with MCL, similar to the effect of MYC-EC in DLBCL patients. ${ }^{47}$ Multivariate analysis confirmed that MYC-EC is not a poor prognostic factor in MCL.

MYC/BCL2 DHL is well known as a subset of large B-cell lymphoma with a poor prognosis. Although MCL with MYC-R has been originally suggested as one type of DHL (CCND1 and MYC), ${ }^{20}$ it has been excluded from the category of high-grade B-cell lymphoma with MYC and $B C L 2$ and/or BCL6 rearrangements in the 2017 WHO classification, and instead retained in the MCL category. In this study, we compared of these two groups and showed both similarities and differences. Compared with patients with $M Y C / B C L 2$ DHL, MCL patients with $M Y C-\mathrm{R}$ more often presented with bone marrow involvement, Ann Arbor stage IV disease, and more frequent CD5 expression. MCL patients with MYC-R also had a poorer OS, however, this last finding did not hold true in patients with de novo disease. In contrast, elevated serum LDH level and more frequent $\mathrm{CD} 10$ and BCL6 expression were more often observed in the MYC/BCL2 DHL group. Overall, these features support the position in the WHO classification that so-called double hit MCL is best kept in the MCL category.

In conclusion, MYC-R is significantly associated with blastoid morphology and CD10 expression in MCL. MCL patients with MYC-R have a very aggressive clinical course and a poor prognosis, similar to patients with $M Y C / B C L 2$ DHL and significantly worse than MCL patients without MYC-R. However, the presentation of patients with MCL associated with MYC-R differs from patients with MYC/BCL2 DHL supporting the exclusion of MCL with $M Y C-R$ from the category of high-grade B-cell lymphoma with $M Y C$ and BCL2 and/or BCL6 rearrangements. MCL with $M Y C$-EC has a prognostic impact intermediate between patients with $M Y C-\mathrm{R}$ and patients with normal MYC. These results suggest that MCL patients with different $M Y C$ status may need different treatment strategies. We recommend using MYC immunohistochemistry as a screening tool to test MYC-R by FISH in blastoid/pleomorphic MCL.

\section{Disclosures}

No conflicts of interest to disclose.

\section{Contributions}

$L W, G T, W H$ and $S L$ performed research; $L W$ and $S L$ per-formed data analysis; $L W, G T, L J M, J X, W H, C C Y, M W$, PJ, PL and SL wrote the manuscript; SL supervised the study. 


\section{References}

1. Jares P, Colomer D, Campo E. Molecular pathogenesis of mantle cell lymphoma. J Clin Invest. 2012;122(10):3416-3423.

2. Vose JM. Mantle cell lymphoma: 2017 update on diagnosis, risk-stratification, and clinical management. Am J Hematol. 2017; 92(8):806-813.

3. AMaddocks K. Update on mantle cell lymphoma. Blood. 2018;132(16):1647-1656.

4. Sander B, Quintanilla-Martinez L, Ott G Xerri L, Kuzu I, Chan JK, et al. Mantle cell lymphoma--a spectrum from indolent to aggressive disease. Virchows Arch 2016:468(3):245-257.

5. Lovec H, Grzeschiczek A, Kowalski MB, Moroy T. Cyclin D1/bcl-1 cooperates with myc genes in the generation of B-cell lymphoma in transgenic mice. EMBO J. 1994;13(15):3487-3495.

6. Hao S, Sanger W, Onciu M, Lai R, Schlette EJ, Medeiros LJ. Mantle cell lymphoma with 8q24 chromosomal abnormalities: a report of 5 cases with blastoid features. Mod Pathol. 2002;15(12):1266-1272

7. Onciu M, Schlette E, Medeiros LJ, Abruzzo LV, Keating M, Lai R. Cytogenetic findings in mantle cell lymphoma cases with a high level of peripheral blood involvement have a distinct pattern of abnormalities. Am J Clin Pathol. 2001;116(6):886-892.

8. Klapproth K, Wirth T. Advances in the understanding of MYC-induced lymphomagenesis. Br J Haematol. 2010; 149(4):484-497.

9. Sewastianik T, Prochorec-Sobieszek M, Chapuy B, Juszczynski P. MYC deregulation in lymphoid tumors: molecular mechanisms, clinical consequences and therapeutic implications. Biochim Biophys Acta. 2014;1846(2):457-467.

10. Kluin PM, Harris NL, Stein H, et al. Highgrade B-cell lymphoma. In: Swerdlow $\mathrm{SH}$, Campo E, Harris NL, et al. eds. WHO Classification of Tumours of Haematopoietic and Lymphoid Tissues. Lyon, France: IARC. 2017:335-341.

11. Swerdlow SH, Campo E, Seto M, and Muller-Hermelink H.K. Mantle cell lymphoma. In: Swerdlow SH, Campo E, Harris $\mathrm{NL}$, et al, ed. WHO Classification of Tumors of Hematopoietic and Lymphoid Tissues. Revised $4^{\text {th }}$ ed. Lyon, France: IARC. 2017

12. Lin P, Dickason TJ, Fayad LE, et al. Prognostic value of MYC rearrangement in cases of B-cell lymphoma, unclassifiable, with features intermediate between diffuse large B-cell lymphoma and Burkitt lymphoma. Cancer. 2012;118(6):1566-1573.

13. Landsburg DJ, Falkiewicz MK, Maly J, et al. Outcomes of patients with double-hit lymphoma who achieve first complete remission. J Clin Oncol. 2017;35(20):2260-2267.

14. Li S, Lin P, Fayad LE, et al. B-cell lymphomas with MYC/8q24 rearrangements and $\quad$ IGH ${ }^{\Theta} \mathrm{BCL} 2 / \mathrm{t}(14 ; 18)(\mathrm{q} 32 ; \mathrm{q} 21): \quad$ an aggressive disease with heterogeneous histology, germinal center B-cell immunophenotype and poor outcome. Mod Pathol. 2012;25(1):145-156

15. Li S, Saksena A, Desai P, et al. Prognostic impact of history of follicular lymphoma, induction regimen and stem cell transplant in patients with MYC/BCL2 double hit lymphoma. Oncotarget. 2016;7(25):3812238132

16. Li S, Seegmiller AC, Lin P, et al. B-cell lymphomas with concurrent MYC and BCL2 abnormalities other than translocations behave similarly to MYC/BCL2 double-hit lymphomas. Mod Pathol. 2015;28(2):208217.

17.Li S, Huang W, Oki Y, Medeiros JL. MYC/BCL2/BCL6 triple hit lymphoma: A study of 33 patients who had an aggressive clinical course similar to patients with double hit lymphomas. J Clin Oncol. 2017; (35):7559.

18. Petrich AM, Gandhi M, Jovanovic B, et al. Impact of induction regimen and stem cell transplantation on outcomes in double-hit lymphoma: a multicenter retrospective analysis. Blood. 2014;124(15):2354-2361.

19. Ott G, Rosenwald A, Campo E. Understanding MYC-driven aggressive B-cell lymphomas: pathogenesis and classification. Blood. 2013;122(24):3884-3891.

20. Aukema SM, Siebert R, Schuuring E, et al. Double-hit B-cell lymphomas. Blood. 2011; 117(8):2319-2331.

21. Li S, Desai P, Lin P, et al. MYC/BCL6 double-hit lymphoma (DHL): a tumour associated with an aggressive clinical course and poor prognosis. Histopathology. 2016;68(7):1090-1098

22. Landsburg DJ, Petrich AM, Abramson JS, et al. Impact of oncogene rearrangement patterns on outcomes in patients with doublehit non-Hodgkin lymphoma. Cancer. 2016; 122(4):559-564.

23. Kluin PM., Campo E, Harris NL, Jaffe ES, et al. High Grade B-Cell Lymphoma. In: Swerdlow SH, Campo E, Harris NL, Jaffe $E S$, et al., ed. WHO Classification of Tumours of Haematopoietic and Lymphoid Tissues. Revised $4^{\text {th }}$ Edition ed. Lyon, France: IARC. 2017

24. Au WY, Horsman DE, Viswanatha DS, Connors JM, Klasa RJ, Gascoyne RD. 8q24 translocations in blastic transformation of mantle cell lymphoma. Haematologica. 2000;85(11):1225-1227.

25. Delas A, Sophie D, Brousset P, Laurent C. Unusual concomitant rearrangements of Cyclin D1 and MYC genes in blastoid variant of mantle cell lymphoma: case report and review of literature. Pathol Res Pract. 2013;209(2):115-119.

26. Hu Z, Medeiros LJ, Chen Z, et al. Mantle cell Lymphoma with MYC rearrangement: a report of 17 patients. Am J Surg Pathol. 2017;41(2):216-224

27. Reddy K, Ansari-Lari M, Dipasquale B. Blastic mantle cell lymphoma with a Burkitt translocation. Leuk Lymphoma. 2008:49(4):740-750.

28. Setoodeh R, Schwartz S, Papenhausen P, et al. Double-hit mantle cell lymphoma with MYC gene rearrangement or amplification: a report of four cases and review of the literature. Int J Clin Exp Pathol. 2013; 6(2):155-167.

29. Xu J, Li S. Triple-hit blastoid mantle cell lymphoma presenting like acute leukemia. Blood. 2017;129(18):2593

30. Hans CP, Weisenburger DD, Greiner TC, et al. Confirmation of the molecular classification of diffuse large B-cell lymphoma by immunohistochemistry using a tissue microarray. Blood. 2004;103(1):275-282

31. Slotta-Huspenina J, Koch I, de Leval L, et al. The impact of cyclin D1 mRNA isoforms, morphology and p53 in mantle cell lymphoma: p53 alterations and blastoid morphology are strong predictors of a high proliferation index. Haematologica. 2012; 97(9):1422-1430

32. Visco C, Tzankov A, Xu-Monette ZY, et al. Patients with diffuse large B-cell lymphoma of germinal center origin with BCL2 translocations have poor outcome, irre- spective of MYC status: a report from an International DLBCL rituximab-CHOP Consortium Program Study. Haematologica. 2013;98(2):255-263.

33. Ribera-Cortada I, Martinez D, Amador V, et al. Plasma cell and terminal B-cell differentiation in mantle cell lymphoma mainly occur in the SOX11-negative subtype. Mod Pathol. 2015;28(11):1435-1447.

34. Saksena A, Yin CC, Xu J, et al. CD23 expression in mantle cell lymphoma is associated with CD200 expression, leukemic non-nodal form, and a better prognosis. Hum Pathol. 2019;89:71-80.

35. Huang W, Medeiros LJ, Lin P, et al MYC/BCL2/BCL6 triple hit lymphoma: a study of 40 patients with a comparison to MYC/BCL2 and MYC/BCL6 double hit lymphomas. Mod Pathol. 2018;31(9):14701478 .

36. McGowan-Jordan J, Simons A, Schmid M An International System for Human Cytogenetic Nomenclature (ISCN 2016) Recommendations of the International Standing Commitee on Human Cytogenetic Nomenclature. Unionville, USA: Karger. 2016.

37. Hoster E, Dreyling M, Klapper W, et al. A new prognostic index (MIPI) for patients with advanced-stage mantle cell lymphoma. Blood. 2008:111(12):558-565.

38. Zhou J, Hu L, Zuo M, Zhou Y, Li G, Zhang $X$. An uncommon case of double-hit mante cell lymphoma that demonstrates transformation process. Am J Clin Pathol. 2019;153(1):49-57.

39. Vincent-Fabert C, Fiancette R, Rouaud P, et al. A defect of the INK4-Cdk4 checkpoint and Myc collaborate in blastoid mantle cell lymphoma-like lymphoma formation in mice. Am J Pathol. 2012;180(4):1688-1701.

40. Lee J, Zhang LL, Wu W, et al. Activation of MYC, a bona fide client of HSP90, contributes to intrinsic ibrutinib resistance in mantle cell lymphoma. Blood Adv. 2018; 2(16):2039-2051.

41. Zhang X, Chen X, Lin J, et al. Myc represses miR-15a/miR-16-1 expression through recruitment of HDAC3 in mantle cell and other non-Hodgkin B-cell lymphomas. Oncogene. 2012;31(24):3002-3008.

42. Chisholm KM, Bangs CD, Bacchi CE, Molina-Kirsch H, Cherry A, Natkunam Y. Expression profiles of MYC protein and MYC gene rearrangement in lymphomas. Am J Surg Pathol. 2015;39(3):294-303.

43. Oberley MJ, Rajguru SA, Zhang C, et al Immunohistochemical evaluation of MYC expression in mantle cell lymphoma. Histopathology. 2013;63(4):499-508

44. Wang XJ, Medeiros LJ, Lin P, et al. MYC cytogenetic status correlates with expression and has prognostic significance in patients with MYC/BCL2 protein doublepositive diffuse large B-cell lymphoma. Am J Surg Pathol. 2015;39(9):1250-1258.

45. Miao Y, Lin P, Wang W, Jeffrey Medeiros L, Lu X. CCND1-IGH Fusion-Amplification and MYC Copy Number Gain in a Case of Pleomorphic Variant Mantle Cell Lymphoma. Am J Clin Pathol. 2016; 146(6):747-752

46. Yi S, Zou D, Li C, et al. High incidence of MYC and BCL2 abnormalities in mantle cell lymphoma, although only MYC abnormality predicts poor survival. Oncotarget. 2015;6(39):42362-42371

47. Quesada AE, Medeiros LJ, Desai PA, et al Increased MYC copy number is an independent prognostic factor in patients with diffuse large B-cell lymphoma. Mod Pathol. 2017;30(12):1688-1697. 